\title{
O PAPEL DAS CLASSES MÉDIAS BRASILEIRAS NO MOVIMENTO REPUBLICANO (*).
}

Têm sido bastante ventilados ùltimamente a contribuição das classes médias brasileiras em nosso movimento republicano e seu papel decisivo no advento da República em 1889. Não se tem procurado fazer uma distinção entre os têrmos "classe média" e "burguesia", nem entre os elementos rurais e urbanos, gerando assim uma confusão na maneira de se conceber a evolução social brasileira e a participação das diversas camadas da população no processo político. E' verdade que o estado atual da investigação histórica em nosso país não nos permite ainda ter uma visão nítida da nossa história social. Alguns trabalhos entretanto, como o de S. J. Stein sôbre Vassouras e o Vale Médio do Paraíba (1) e de Lucila Herrmann sôbre Guaratinguetá (2) permite-nos vislumbrar algumas características de nossa evolução social, pelo menos em certas áreas e para determinado período que abrange aquêle que mais nos interessa, isto é, a segunda metade do século XIX.

Antes, porém, de procurarmos tirar algumas conclusões ou pelo menos levantar alguns problemas referentes à sociedade brasileira, tentaremos conceituar os têrmos classe média e burguesia conforme o seu emprêgo na literatura universal. Tem-se, em geral, reservado a palavra burguesia para designar setores sociais nitidamente urbanos. E' um setor amplo, abrangendo diferentes camadas como a alta, a média e a pequena burguesia, sendo muitas vêzes difícil estabelecer uma nítida

\footnotetext{
(*). - Conferência proferida na Faculdade de Filosofia, Ciências e Letras de Marília (Estado de São Paulo), em 8 de novembro de 1963 (Nota da Redação).

(1). - S. J. Stein, Vassouras. A Brazilian Coffee Country, 1850-1900. Cambridge, Mars. 1957, e "Aspectos do Crescimento e Declínio da Lavoura de café no Médio Pará́ba, 1850-1860", in Revista de História da Economia Brasileira, São Paulo, ano I, n. 1 (junho, 1953), pp. 22-41.

(2). - Lucila Herrmann, "Evolução da Estrutura Social de Guaratinguetá num período de trezentos anos", in Revista de Administração, II, n. ${ }^{\mathrm{s}}$ 5-6 (março-junho), pp. 3-326.
} 
linha divisória entre elas. Freqüentemente quando se menciona a burguesia tem-se em mente a alta e a média, pois quando se tenciona especificar a camada mais pobre, usa-se comumente o qualificativo "pequena", pequena burguesia.

Já o têrmo "classe média" é ainda mais vago. Merece quando muito, conforme observa Jean Lhomme, na sua obra sôbre a alta burguesia francesa no século XIX (3), ser considerada como simples grupos sociais, dada a sua falta de homogeneidade. Daí a conveniência de se usar o plural. Refere-se indistintamente seja a grupos urbanos, confundindo-se muitas vêzes com a média burguesia, seja a elementos rurais, acepção particularmente usada no Brasil onde o grupo do campesinato não tem sido bem caracterizado .

A maneira como se tem processado a exploração agrícola no Brasil tem confundido nossa visão a propósito dos elementos que constituem nossa sociedade rural. Exploração de tipo altamente capitalista e eminentemente predatória, a nossa grande lavoura (e refiro-me particularmente à lavoura cafeeira) se tem, por um lado, contribuído ao desbravamento do pais e à integração na nação de extensas áreas vazias e desaproveitadas, tem, por outro deixado atrás de si a devastação e o empobrecimento. A sorte dêsses setores vítimas da passagem destruidora da grande lavoura, não tem sido, em geral, muito considerada pelos estudiosos de nossos problemas. Ora a ação predatória da grande lavoura e particularmente da lavoura cafeeira tem provocado sérias modificações na estrutura social dessas áreas e dado-lhes uma feição bem mais complexa do que pretende a simplificada versão de um Brasil rural dividido em senhores latifundiários e um proletariado rural.

Só levando em conta essa complexidade podemos compreender a evolução político-social do Brasil e melhor caracterizar os seus diversos componentes. O Professor Mollat, em sua aula inaugural no Departamento de História da Faculdade de Filosofia, Ciências e Letras da Universidade de São Paulo em 1961, chamava a atenção para o aspecto qualitativo da História Econômica, lembrando que é a qualidade, mais do que a quantidade que importa em História.

Aplicando essas observações ao campo da história social verifica-se a necessidade de qualificar o tipo de sociedade estudada. Não basta saber que apresenta diversas camadas, mas o que essas camadas representam e significam. O Prof. Sérgio

(3). - J. Lhomme, La Grande Bourgeoise au Pouvoir. Paris, 1960, p. 4. 
Buarque de Holanda, ao referir-se à burguesia portuguêsa quatrocentista, vale-se do mesmo princípio e insiste na necessidade de diferenciar essa burguesia portuguêsa não só de outras suas contemporâneas como de outras mais recentes. Diz êle, por exemplo,

"seria uma burguesia portuguêsa e quatrocentista, ambiciosa de prêsas e honras, mas alheia a certas virtudes mais prosaicas que nos evoca hoje êsse conceito" (4).

E' nessa direção que devemos nos orientar para que possamos efetuar reais avanços no setor dos estudos brasileiros. Não basta distinguirmos no setor agrário uma categoria que domina e outra que é dominada. Uma diferenciação existe entre o fazendeiro de café do Vale do Paraíba e o do Oeste Paulista. Mesmo neste Oeste Paulista é possível distinguir entre o elemento dinâmico que avança e se enriquece e aquêle que permanece e se empobrece. Seria legítimo incluir a primeira categoria nos quadros de uma sociedade puramente rural? Não seria êle mais pròpriamente o instrumento de interêsses urbanos comerciais e bancários por sua vez vinculados, ao que tudo indica, ao capital internacional? Richard Morse em sua biografia da cidade de São Paulo (5) chama a atenção para a conexão entre a metrópole paulista e a expansão para o Oeste e a mentalidade industrialista e capitalista dêsse tipo de fazendeiro. Muitos, a grande maioria provàvelmente nem mesmo residiam em suas fazendas, mas na capital onde engrossavam as fileiras da alta burguesia cujos interêsses se entrozavam perfeitamente e cujas atividades se exerciam tanto no setor agrário, como no comercial, bancário e industrial (6). Celso Furtado, aliás, ao analisar a gestação da economia cafeeira (6a) refere-se a êsse gênero de atividade como sendo pròpriamente uma emprêsa. Seria, pois, mais adeqüado usarmos o têrmo de empresário ao designarmos êsse tipo de cafeicultor.

Ultrapassada a fase pròpriamente lucrativa da exploração agrícola, os capitais particulares perdiam grande parte do seu interêsse por êsse gênero de atividade (7), o crédito tornava-se

(4). - Sérgio Buarque de Holanda, "A Historiografia portuguêsa", in Suplemento Literário de “O Estado de São Paulo", V, n.o 207 (12-9-1960), p. 2.

(5). - Richard Morse, From Community to Metropolis. A biography of São Paulo, Brazil. Gamesville. 1958, p. 115 .

(6). - Ioid., p. 170 .

(6a). - Celso Furtado, Formação Econômica do Brasil. Rio de Janeiro, 1959, pp. 133-140.

(7). - S. J. Stein, op. cit., p. 252 . 
mais difícil e precário. Assistia-se então à ruralização pròpriamente dita do fazendeiro, isto é, daquele que se apegava à sua terra ou não tinha meios de avançar. Se tomarmos outras camadas sociais, particularmente as chamadas classes médias cuja heterogeneidade, como já dissemos, é ainda maior, semelhantes distinções se impõem, se quisermos deslindar o fio da meada da nossa história social e a participação dos diferentes grupos sociais na política brasileira.

Para compreendermos o papel de certas classes médias no advento do regime republicano no Brasil, é necessário conhecermos as mudanças sociais que se efetuaram na segunda metade do século XIX, como resultado das transformações econômicas que se operaram nessa época. El nesse sentido, os trabalhos já mencionados de Stein e L. Herrmann nos fornecem alguns pontos de partida.

Ambos constatam um fenômeno de concentração da propriedade territorial e conseqüentemente de uma maior diferenciação social. Stein nos mostra como os principais fazendeiros de Vassouras burlavam a Lei das Partilhas que obrigava a divisão da propriedade entre os herdeiros, constituindo sociedades e consórcios ou estendendo as terras pelo casamento entre os clãs ou dentro do próprio clã (8). Lucila Herrmann é ainda mais explícita. Diz ela:

“A tendência dos proprietários rurais a aumentarem suas propriedades por anexação, pela intensidade com que se manfiesta e pela forma que apresenta durante o ciclo do café, parece ser uma fôrça originária dêste ciclo".

Nota a seguir que os latifúndios e grandes propriedades existentes anteriormente não exprimiam uma tendência anexadora. Apenas se conservavam graças às condições sociais e jurídicas, vigentes na época. E continua:

"No ciclo do café as condições se alteram: a Lei dos Morgados cede lugar à das Partilhas”.

Em vez, porém, de assistirmos a um fracionamento da propriedade rural, dá-se justamente o inverso (9) . A autora, aliás, sustenta a tese de que prèviamente ao ciclo cafeeiro, em Guaratinguetá, embora existissem alguns latifúndios, predomina-

\footnotetext{
(8). 一 Ibid., p. 18.

(9). - Luclla Herrmanin, op. cit., pp. 12s-124.
} 
va contudo a pequena propriedade (10). A situação modificase com a invasão do café:

"Os proprietários, enriquecidos durante o periodo, curto mas rendoso do ciclo dos engenhos, aumentando sua renda nos primeiros anos do ciclo do café, com larga escravaria e fortes fundos em prata, ouro e cobre encontrando, em seu redor, os pequenos proprietários cada vez mais feridos pela Lei das Partilhas, aumentam seus domínios por meio da compra das terras circundantes à fazenda, comprando ou formando sítios mais distantes, cuja direção entregam aos filhos" (11).

Verifica-se pois um remanejamento da estrutural social. Numa sociedade relativamente igualitária, se considerarmos apenas os donos da terra, a economia cafeeira aliada à uma nova legislação relativa à propriedde territorial, introduz uma diferenciação social mais nítida, criando a divisão entre o grande fazendeiro e o pequeno lavrador. Aquêles que não tiveram meios de participar ou de se integrarem na nova forma de exploração agrária são condenados à ruína .

"A própria situação de prestígio social precipita a decadência", diz L. Herrmann. "Pretendentes a familias tradicionais, com ricas mansões na vila, vêm-se na contingência, não obstante as sucessivas dificuldades econômicas trazidas pela Lei das Partilhas, a sustentar uma posição social prêsa a gastos para os quais já não estão aparelhados" (12).

A solução é o êxodo.

"O reduto das familias agricolas empobrecidas pela Lei das Partilhas é a Vila, onde vivem do aluguel de seus escravos, de costuras e prendas domésticas, de cargos públicos" (13).

Se há assim, por um lado, um empobrecimento de uma parte do setor agrário, verifica-se, por outro, graças às oportunidades oferecidas pelo café, a ascenção de elementos das camadas sociais mais baixas, daqueles que não possuiam terras, a terceira classe, segundo a designação adotada pela autora já mencionada:

(10). - Mbid., pp. 68-64.

(11). - Ibld., p. 124 .

(12). - Ibid., p. 134 .

(13). - Ibid., p. 148 . 
"O ciclo do café traz vantagens excepcionais ao comércio de beira de estrada, quando unido ao plantio do. café. Este era um produto de venda certa, sem requisitar máquinas de transformação. Vendido em "côco" na porta do produtor, aos compradores das estradas, permitia aos elementos da terceira classe - "plantar café. em terra alheia" - um lugar fácil sem nenhum dispêndio e sem a dependência do maquinário do senhor de. terras" (14).

$\mathbf{E}^{\prime}$ provàvelmente também nesse sentido que alguns autores referem-se ao papel democratizante do café em contraste com a função aristocratizante da cana de açúcar (15). Mas, como observa ainda L. Herrmann:

"Outras fôrças além do café favorecem a ascenção" dos elementos da terceira classe: a elevação do salário do trabalhador agricola, do jornal, a renda do trabalho de achego" (16).

Verifica-se pois em Guaratinguetá a formação de dois tipos de classe média: uma que se constitui graças a ruína de antigos senhores rurais e.que é portanto uma classe destituída e outra, ao contrário, representada por elementos em ascenção. social. A mentalidade, as atitudes, o comportamento dêsses dois segmentos das classes médias não serão, lògicamente, os mesmos em face das transformações por que passa o Brasil na segunda metade do século XIX. Enquanto que os segundos. se mostram mais permeáveis à infiltração de traços culturais. exógenos, afirma L. Herrmann,

"o grupo constituído pelos descendentes da classe que ocupou, durante três séculos, posição de dominância na. estrutura social se mostra mais reacionário às fôrças que solapam a coesão moral das famílias e os costumes (...) Por haver ocupado, durante três séculos, posição de liderança na estrutura social, êsse grupo, atualmente destituído de quase todos os direitos e prerrogativas anteriores - valor econômico, valor politico, classe social - ocupa, ainda no consenso social a posição anterior. Duas fôrças agem assim, impelindo-o a perpetuar no presente os padrões culturais do passado - a própria opinião e a opinião coletiva" (17).

(14). - Ibid., p. 136 .

(15). - Sérgio Buarque de Holanda, Raízes do Brasil. Rio de Janeiro, 1948, p., 257.

(16). - L. Herrmann, op. cit., p. 136.

(17). - Ibid., p. 5. 
Não podemos pois confundir os dois grupos ao tentarmos analisar sua eventual participação no processo político. Diferenças assinalarão necessàriamente sua atuação nesse processo.

As conclusões a que chegou L. Herrmann ao estudar Guaratinguetá podem, de modo geral, ser estendidas, pelo menos provisòriamente, a tôda a área onde a introdução da cultura cafeeira veio encontrar uma sociedade já estruturada em moldes semelhantes. Os fatos observados por Stein em Vassouras a tanto nos autorizam. Já nas zonas novas o processo, òbviamente, deve ter sido diferente, com uma predominância incontestável das camadas em ascenção.

Não conhecemos estudos semelhantes aos mencionados e relativos às áreas não cafeeiras do Brasil. No Norte e Nordeste, a decadência dos produtos agrícolas tradicionais, provocando o empobrecimento geral da região, deve ter contribuído para a formação de uma nova classe mais ou menos destituída análoga à do Vale do Paraíba, pelo menos quanto a seu apêgo aos padrões culturais do passado. A grande diferença que parece existir na estrutura social, pelo menos nos aspectos que nos interessam nesse momento, entre a região do açúcar e a da primitiva zona do café, é que no Nordeste é maior a proletarização das classes baixas enquanto que no Vale do Paraíba durante a expansão cafeeira o problem social mais agudo é o da ruína de antigos proprietários rurais. Silva Jardim durante sua viagem de propoganda ao Norte nota, com certa surprêsa, a existência dessa massa proletária de Recife, expelida provàvelmente pelo empobrecimento da zona rural, mas sem entretanto encontrar na cidade um ofício certo. E' uma cohorte de bravos, no dizer de Silva Jardim.

"Ela tem o instinto da revolta contra tôdas as prepotências e tiranias, mas é suscetivel de sacrificar a mesma liberdade quando mal guiada pelos especuladores políticos" (18).

Já o mesmo fenômeno não se apresenta, pelo menos com a mesma gravidade, no Vale do Paraíba. Segundo L. Herrmann

"há uma tendência menor a uma alta concentração de indivíduos livres sem nenhum pecúlio (...) indicando que o apogeu econômico trazido pelo café, se, de um lado, tende a marcar uma diferença social muito pronunciada, tende, igualmente, a reduzir a freqüência da classe sem pe-

(18). - Silva Jardim, Memórias e Viagens. Lisboa, 1894, p. 392. 
cúlio. As classes mais freqüentes passam a ser a das que auferem lucros pequenos ou a dos possuidores de pequenas propriedades" (19).

Essas considerações gerais sôbre o Nordeste e as indicações que sôbre o Vale do Paraíba nos dão L. Herrmann e S. J. Stein, cremos serem suficientes para que possamos esboçar, sem que isso signifique excesso de audácia, a tese que pretendemos apresentar nessa palestra, ou seja que certos segmentos de classe média que tiveram papel ativo no movimento republicano, representavam valores do passado ameaçados ou já condenados pelas transformações do presente e que recorriam as instituições republicanas na ilusão de que o nôvo regime pudesse restaurar uma ordem já superada pelo próprio regime imperial.

A'o lado dessas fôrças do passado encontramos as fôrças vivas do presente, isto é, as camadas sociais em ascenção, seja de alta ou pequena burguesia, seja da cidade ou seja do campo, às quais o aparelho emperrado das instituições monárquicas já não mais satisfazia. Instiladas com um nôvo fermento, o da capitalismo industrial, anciavam por uma modernização das instituições e principalmente pela eliminação das peias políticas e econômicas impostas pelo Império.

Sua ação contra as instituições imperiais foi naturalmente reforçada pelo ressentimento das classes médias destituídas e mesmo, à última hora, pelo descontentamento dos ex-senhores de escravos: Mas foram elas que conduziram os acontecimentos e foi em seu proveito que se instaurou o nôvo regime. Do ponto de vista social constituem várias camadas e vários grupos, cuja heterogeneidade nos impede de classificá-las como burguesas. Tudo parece indicar que só a partir da República e particularmente da época de Floriano Peixoto é que se começam a aglutinar os elementos de uma classe nova, de uma nova burguesia. Anteriormente os incipientes elementos quer de pequena, quer de alta burguesia, estavam ainda muito vinculados aos interêsses e aos valores predominantemente agrários do país para se constituirem numa classe distinta e autônoma. A urbanização é ainda incipiente, no Império, embora ela tenha se acentuado com a expansão cafeeira. A riqueza proporcionada pelo café permitiu um maior desenvolvimento do comércio e do artezanato nas cidades da zona cafeeira; a cidade proporcionou, como já vimos, um refúgio à população em-

(19). - L. Herrmann, op. cit., p. 147. 
pobrecida da zona rural, e principalmente como nota o Prof. Sérgio Buarque de Holanda, o café exigindo uma redução da lavoura de subsistência

\footnotetext{
"aumentou, por conseguinte, a necessidade do recurso aos centros urbanos distribuidores dos mantimentos, que outrora se criavam no próprio lugar" (20).
}

Há ainda, porém, uma estreita vinculação entre cidade e campo. Só a partir da República e da crescente industrialização do Brasil é que começa a se acentuar a autonomia do elemento urbano. Mas no início da Éra Republicana é ainda um grupo muito debil para atuar decisivamente sôbre os destinos da nação.

Ao lado dêsse setores em ascenção encontramos no movimento republicano, elementos das classes médias que chamamos destituídas e que constituiam um agrupamento mais homogêneo provàvelmente porque, pertencendo em geral ao antigo estoque ibérico, apresentavam uma maior unidade cultural e social. Essa homogeneidade refletia-se em sua concepção peculiar do regime republicano, pois os seus representantes mais significativos embora não pertencessem à corrente ortodoxa defendiam as idéias republicanas dos Positivistas, isto é, mostravam-se favoráveis a uma concentração de poderes no executivo - o que êles chamavam de ditadura republicana que não se confundia, segundo êles, com a tirania, e condenavam o regime da democracia representativa. Representavam, como dissemos, valores do passado e talvez isso explique porque, embora tendo tido certa importância no movimento republicano, as idéias positivistas não tiveram aceitação no nôvo regime, uma vez instaurado êste.

Para ilustrar as idéias defendidas por esta corrente, escolhemos dois próceres republicanos. Um pernambucano, Anibal Falcão; outro fluminense, Silva Jardim; ambos provenientes de regiões onde, a que tudo indica, as condições sócio-econômicas haviam favorecido a formação dessa classe média destituída, a que já nos referimos.

Nasceu Anibal Falcão em Recife, pertencendo pelo lado materno à antiga família pernambucana; enquanto que o pai, filho de portuguêses, estava ligado ao serviço público: tinha o privilégio do registro taquigráfico de Assembléias Provinciais. Foi Anibal Falcão quem, por ocasião do golpe de 15 de

(20). - Sérgio Buarque de Holanda, op. cit., p. 260 . 
novembro, enquanto os seus autores ainda hesitavam em proclamar a República, teve a iniciativa de procurar José do Patrocínio, então vereador da Câmara Municipal do Rio de Janeiro, levando-o a convocar uma sessão em que se proclamou o nôvo regime. O gesto é significativamente ibérico e lembra - dos conquistadores que legalizavam seus pronunciamentos com a sanção do "povo" reunido em câmaras ou juntas. Fundamentalmente ibérico é igualmente o pensamento político de Anibal Falcão. O seu pronunciado localismo leva-o a defender a autonomia municipal, enquanto seu nativismo o faz condenar a colonização estrangeira e repudia o exemplo dos Estados Unidos.

\begin{abstract}
"Essa propaganda de colonização estrangeira", escreve êle, "resulta também da admiração que os nossos democratas - quase todos os são, chamem-se conservadores ou republicanos - manifestam para o que chamam pomposamente progresso dos Estados Unidos. A república americana efetivamente produz muito, mas também cada vez mais degenera de pátria americana em uma verdadeira e imensa sociedade de mercadores, sem passado, sem futuro e com uma religião característica: o culto do Dollar" (21).
\end{abstract}

No manifesto do Partido Republicano de Pernambuco, redigido por êle (22), faz questão de vincular às tradições do passado e às suas tentativas republicanas os esforços nesse sentido despendidos no presente. Depois de atacar o regime constitucional representativo, passa à afirmação dos princípios de igualdade, isto é, à abolição de todo o privilégio, e o de liberdade que considera principalmente como liberdade espiritual, isto é, liberdade religiosa e de ensino. Defendendo o princípio da ditadura republicana tão caro ao Positivismo, Anibal Falcão expõe suas idéias a respeito:

"o regime republicano", diz êle, "exerce-se no campo da ação prática pela concentração das fôrças políticas, isto é, pela ditadura, tão forte quanto responsável, incumbida de permitir a livre expansão de progresso, garantindo a ordem social, acentuando a noção da responsabilidade "moral e legal" dos depositários do poder público".

(21). - Anibal Falcão, Fórmula da Civillzação Brasileira. Rio de Janeiro, s. d, pp. 131-132.

(22). - Ibid., pp. 163-175. 
que difere, segundo êle, da ditadura republicana das monarquias onde o soberano é irresponsável.

E' essa mesma exigência da responsabilidade dos depositários do poder que o faz regeitar o regime representativo, ou parlamentarismo, como diz:

"Como entregar o poder do legislar a uma câmara numerosa ,impossivel de tornar diretamente responsável perante a opinião pública e sem corretivo legal, porque é suposta soberana?" (23).

Para contrabalançar essa concentração de poderes políticos num corpo reduzido de depositários do poder público, advoga, como os demais positivistas, a descentralização administrativa. Mas para Anibal Falcão essa descentralização, ao contrário dos que defendiam um regime federativo, não se devia fazer a favor das províncias, mas sim das câmaras municipais (24).

Embora invoque freqüentemente os princípios e práticas da Revolução Francesa, as idéias de Anibal Falcão lembram mais o populismo de Suarez, segundo o qual a soberania reside no povo como coletividade, sendo as autoridades superiores apenas depositárias dêsse poder, ao contrário das doutrinas individualistas e pactistas que dão ênfase aos direitos individuais.

Anti-individualista ao extremo, Anibal Falcão revela-se também violentamente anti-burguês. Segundo êle a burguesia é em sua época

"pelo seu estreito egoísmo o principal obstáculo à instituição e ao livire funcionamento de um govêrno destinado a favorecer o proletariado, que é no que se resume a verdadeira aspiração do bem público" (25).

O pensamento político de Silva Jardim já não tem a mesma consistência apresentada pelo de Anibal Falcão e enquanto êste era o porta-voz do partido republicano de Pernambuco, Silva Jardim, depois de romper com a direção central do partido, age pràticamente por conta própria, embora apoiado por alguns grupos, particularmente pelos republicanos de Pernambuco.

Antônio Silva Jardim nasceu em Capivarí, então província do Rio de Janeiro, sendo seu pai um pequeno agricultor que

(23). - Ibid., p. 184.

(24). - Ibid., pp. 169-170.

(25). - Ibid, p. 188. 
supria com as funções de mestre-escola a precariedade de suas rendas agrícolas. Consegue formar-se em direito pela escola de São Paulo, embora lutando sempre com dificuldades financeiras, e ingressa, pelo casamento, no clã paulista dos Andradas. Teve, provàvelmente mais do que Anibal Falcão, a oportunidade de um contacto mais íntimo com as camadas sociais em ascenção, o que explica, talvez em parte, o maior calor da sua atuação e um pragmatismo acentuado.

Uma sociedade em contínua mudança, como era a da área cafeeira, não oferecia muitas condições para a existência de sistemas rígidos de pensamento. Essencialmente um propagandista, Silva Jardim não era um teórico como Anibal Falcão e, procurando atingir o mais amplo auditório possível, seu pensamento não se fixava numa linha ideológica muito definida. Ele próprio assim explica a Alberto Tôrres a sua conduta tática:

"Do abstrato ao concreto, da teoria à prática, vai um grande passo. Não podemos formular programa senão para o momento" (26).

Defendia certamente as idéias centrais sustentadas por Anibal Falcão e os positivistas brasileiros, isto é, a ditadura política e a descentralização administrativa. Também como êles manifestava-se contrário ao sistema representativo, embora concordando em admití-lo transitòriamente (27). Suas idéias, porém, não são tão nítidas quanto as de Anibal Falcão. Na questão do Federalismo, por exemplo, defendia tanto a autonomia do município quanto a da província, ao passo que Falcão dava supremacia à autonomia local das comunas. O coletivismo de Jardim também, ao contrário do de Falcão, está mesclado de individualismo. Exemplo típico dessa dualidade de tendências e provàvelmente de uma deliberada confusão ideológica é o seguinte trecho de um de seus discursos:

"Por essa palavra - federal, devemos muitas vêzes entender a autonomia do município e da província, que é a resultante da autonomia individual. E é esta de fato a grande combinação politica, concretizada em um conjunto, em que se associam indivíduos, famílias, municipios, provincias, pátria, coletividade em que é respeitada a li-

(26) - - Silva Jardim, Memórias e Viagens, op. cit., p. 330.

(27). - Mbid., pp. 328-331. 
berdade e a individualidade de cada homem, e a liberdade e a autonomia de cada corporação" (28).

E' interessante notar que o anti-burguesismo de Silva Jardim tinha uma feição mais social e política, enquanto que a posição de Anibal Falcão era mais filosófica. O anti-burguesismo dêste decorre de seu anti-individualismo e de sua atitude contrária ao primado da razão nas relações sociais.. Segundo êle,

"a insurreição do indivíduo contra a espécie — pois em tal consiste o principio da infalibilidade da razão traz como conseqüência o predomínio do egoísmo o que se manifesta não só pela ruptura da solidariedade, como principalmente pela quebra radical de tôda continuidade. A disciplina social sofre então os mais rudes embates e o correspondente sentimento - a veneração - que preside à essa disciplina é cada vez mais comprimida, ao passo que o orgulho se desenvolve" (29).

Silva Jardim pertencendo à uma área geográfica que sofria profundas modificações econômicas já tem, ao contrário, uma certa noção, embora vaga e elementar, da oposição de classes sociais. Distingue de um lado, segundo suas palavras,

"elementos representantes de tradições egoístas, aristocráticas, de privilégio e de família, de espírito de conquista e de retrogradação", e de outro "os fortes embora novos se bem que muito domados elementos populares de paz e de trabalho, de liberdade e de fraternidade, de progresso e de ordem" (30).

Quanto ao seu anti-burguesismo, confunde-se com o seu profundo sentimento anti-orleanista. Considerava êste

"o ecletismo, a covardia do pensamento, em Filosofia. Em Política, aplicação do sistema constitucional inglês falseado (...). Em Política ainda, o censo eleitoral privilégio da burguesia (...) a política mesquinha do egoísmo e da corrupção" (31).

$\mathrm{O}$ que, porém, muito provàvelmente lastreava, tanto em Anibal Falcão como em Silva Jardim, essa atitude anti-burgue-

\footnotetext{
(28). - Silva Jardim, Pela Republica contra a Monarchia. Conferências Populares, 1889, p. 15.

(29). - Anibal Falcão, op. cit., p. 116.

(30). - Silva Jardim, A Pátria em Perigo. Sáo Paulo, 1888, p. 6.

(31). - Ibid., pp. 25-26.
} 
sa, era a ameaça que a ascenção e predomínio dessa classe representava para os padrões tradicionais da cultura brasileira. Ora, a República foi precisamente a vitória de tudo quanto ambos combatiam: o individualismo, o liberalismo econômico, o predomínio do capital e o regime liberal representativo. Não é de se admirar que ambos fôssem bem cêdo eliminados da cena republicana e tomassem logo o caminho do exílio na Europa onde Silva Jardim encontraria sua dramática morte.

A primeira República representando fundamentalmente o triunfo das correntes pròpriamente federalistas e liberais, veio, incontestàvelmente, favorecer as camadas mais dinâmicas da sociedade brasileira, relegando a segundo plano os elementos que não se integravam na nova ordem. Entretanto, o fato do papel dessas classes médias destituídas não ter sido o mais representativo para o advento da República, não significa que tenham deixado de atuar na política brasileira. Seu ressentimento será sempre um fator no jôgo político e possivelmente um fator de ordem capital. Tendo em vista o tipo de economia a que tem estado sujeito o Brasil, com o decorrente e contínuo empobrecimento das áreas exploradas, as fileiras dessa classe são permanentemente engrossadas e renovadas por novos contingentes. Ela certamente deve desempenhar seu papel nos movimentos nacionalistas e esquerdistas da atualidade, pelo menos em alguma de suas correntes. Seria de grande interêsse para a compreensão dos problemas brasileiros verificar até que ponto estas correntes se prendem ao passado, a seus valores e padrões culturais, preteridos e suplantados pelos novos modelos introduzidos pela economia capitalista e consagrados pelo regime liberal da República. Não conservariam certas tendências esquerdistas atuais alguns de nossos componentes tradicionais, como outrora certas tendências republicanas, para perpetuar caracteres ibéricos, adotaram as roupagens mais modernas e mais aceitáveis do positivismo?

De qualquer maneira esperamos que esta palestra tenha contribuído para demonstrar a complexidade do fenômeno político brasileiro e a impossibilidade de rotular qualquer de seus processos como simples luta de classes. A oposição dos grupos existe, naturalmente, mas nem sempre podemos enquadrar êsses grupos em classes distintas; e nem sempre as reivindicações de grupos de classe média correspondem exatamente ao que se convencionou esperar dessa classe. No Brasil, em to- 
do o caso, exemplos há de um certo setor, correspondente a esta classe, que se manifesta antagônico a uma filosofia e a uma política comumente atribuídas à burguesia.

NICIA VILLELA LUZ

Instrutora da Cadeira de História da Civilização Brasileira da Faculdade de Filosofia, Ciências e Letras da Universidade de São Paulo. 